\title{
ANALISIS FAKTOR-FAKTOR YANG MEMPENGARUHI MAHASISWA DALAM MEMAHAMI MATA KULIAH AUDITING (Studi empiris pada mahasiswa Jurusan Akuntansi di Fakultas Ekonomi UNIMUS dan UNISSULA Semarang)
}

\author{
Oleh : \\ Ellya Fuadiyah, \\ Fatmasari Sukesti \\ Fakultas Ekonomi Universitas \\ Muhammadiyah Semarang
}

\begin{abstract}
:
This study aims to analyze the factors that students affect on understanding of auditing course. The study based on the motivation's theory that is developed by Maslow and Big Five Personality's theory that is introduced by Goldberg, then it use the variable understanding of auditing course, motivation, communication skills, and personality. The method used is survey research. Analytical instrument to examine the hipotheses and validity of this study uses Structural Equation Model (SEM), it uses AMOS 21.0 program. Whereas, the program that be used in this study for descriptive statistic and reliability analysis uses SPSS 16.0 program, with notice means and standard deviation for statistic descriptive and cronbach alpha value to determine reliability.The results showed that motivati on, communication skills, and personality a studens positive affect on understanding of auditing course. While communication skills no students positive effect on understanding auditing course.
\end{abstract}

Keywords: auditing course, auditing course understanding, motivation, communication skills, personality 


\section{PENDAHULUAN}

Audit pada saat ini menjadi bagian yang penting dalam dunia akuntansi. Selain pemahaman umum atas pentingnya fungsi audit, peningkatan atas keberadaan auditor dan lembaganya juga menambah pemahaman umum terhadap audit. Lebih lanjut lagi, tuntutan-tuntutan hukum yang biasanya dihadapi oleh auditor dan kerugian keuangan yang terkait dengan tuntutan tersebut memunculkan berbagai dimensi keperilakuan pada diri auditor, khususnya aspek-aspek yang terkait dengan proses pengambilan keputusan dan aktivitas auditor dalam mempertimbangkan sesuatu sebelum mengambil keputusan.

Program pendidikan pada lembaga pendidikan tinggi yang diandalkan untuk pembentukan kompetisi pribadi dan wawasan kebangsaan dalam penelitian ini yaitu mata kuliah auditing. Melalui mata kuliah tersebut diharapkan mahasiswa mendapat bekal dalam hal menjalankan praktek auditing. Keberhasilan program pendidikan khususnya mata kuliah auditing ditandai adanya perubahan perilaku mahasiswa baik dari aspek kognitif, afektif, dan psikomotoriknya sesuai dengan tujuan kurikuler. Perubahan perilaku dalam pembelajaran pada umumnya tercermin dari hasil belajar yang diperoleh mahasiswa.

Untuk memperoleh lulusan mahasiswa yang berkualitas, peran dosen tidaklah penting bila tidak diimbangi dengan dorongan dari dalam mahasiswa itu sendiri. Secara umum tujuan motivasi adalah untuk menggerakkan atau menggugah seseorang agar timbul keinginan dan kemauannya untuk melakukan sesuatu sehingga dapat memperoleh hasil atau mencapai tujuan tertentu (Purwanto, 1990). Menurut Sadirman, motivasi adalah proses yang memberi semangat, arah, dan kegigihan perilaku. Artinya, perilaku yang memiliki motivasi adalah perilaku yang penuh energi, terarah, dan bertahan lama (Sardiman, 2007).

Kemampuan komunikasi juga dianggap sebagai faktor penting untuk mencapai kesuksesan dalam bidang akuntansi khususnya auditing. Kemampuan komunikasi seseorang dapat meningkatkan produktivitas individu maupun kelompok. Setiap orang memiliki kecenderungan terhadap gaya komunikasi tertentu. Hal ini dipengaruhi oleh perpaduan antara hereditas dan faktor lingkungan seseorang. Lebih jauh, proses komunikasi seseorang dipengaruhi oleh gaya komunikasi. Gaya komunikasi merupakan kombinasi dari berbagai komponen, seperti pola suara, gerak mata, ekspresi wajah. Agar dapat berkomunikasi dengan baik, gaya komunikasi haruslah fleksibel, disesuaikan dengan situasi dan gaya komunikasi orang yang diajak berbicara

(Riswanti, 2010).

Kepribadian seseorang juga mempengaruhi gaya komunikasi seseorang. Apakah orang itu pendiam, pasif, ceria, ambisius ataupun mudah bergaul. Kepribadian merupakan pola perilaku, pikiran, dan emosi yang unik dan relatif stabil yang dimiliki individu dalam usahanya untuk menyesuaikan diri dan berinteraksi dengan lingkungannya. Kepribadian terbentuk dari faktor keturunan maupun faktor lingkungan dalam kondisi situasional. Faktor keturunan merujuk pada faktor - faktor yang ditentukan sejak lahir. Sedangkan faktor lingkungan merujuk pada budaya tempat individu dibesarkan, kondisi awal individu, norma keluarga dan kelompok sosial serta pengaruh yang dialami individu sepanjang masa hidupnya.

\section{TUJUAN PENELITIAN}

Penelitian ini bertujuan untuk mengetahui dan menguji pengaruh motivasi, kemampuan komunikasi, dan kepribadian terhadap pemahaman mata kuliah auditing pada mahasiswa akuntansi.

\section{TELAAH PUSTAKA}

Menurut Siagian (2004), teori motivasi belajar dapat dikembangkan menjadi tiga teori turunan, yaitu:

1. Teori Kebutuhan sebagai Hierarki Keseluruhan teori motivasi yang dikembangkan oleh Maslow berintikan pendapat yang mengatakan bahwa kebutuhan manusia dapat diklasifikasikan pada lima hierarki kebutuhan, yaitu:

a. Kebutuhan fisiologis, yaitu kebutuhan untuk menunjang kehidupan manusia seperti makanan, air, pakaian, dan tempat tinggal. Menurut Maslow, jika kebutuhan fisiologis belum terpenuhi, maka kebutuhan lain tidak akan memotivasi manusia.

b. Kebutuhan akan keamanan, yaitu kebutuhan untuk terbebas dari bahaya fisik dan rasa takut kehilangan.

c. Kebutuhan sosial, yaitu kebutuhan untuk bergaul dengan orang lain dan untuk diterima sebagai bagian dari yang lain. 
d. Kebutuhan penghargaan, yaitu kebutuhan untuk dihargai orang lain. Kebutuhan ini akan menghasilkan kepuasan seperti kuasa, prestis, status, dan kebanggaan akan diri sendiri.

e. Kebutuhan untuk aktualisasi diri, yaitu kebutuhan untuk mengaktualisasikan semua kemampuan dan potensi yang dimiliki hingga menjadi orang seperti yang dicita-citakan.

2. Teori Motivasi-Higiene

Teori Motivasi-Higiene dikembangkan oleh Frederick Herzberg yang menyebutkan tiga kebutuhan terendah dalam hirarki kebutuhan Maslow yaitu kebutuhan fisiologis, kebutuhan keamanan, dan kebutuhan sosial sebagai faktor ketidakpuasan (dissatisfaction), artinya pemenuhan kebutuhan-kebutuhan tersebut hanya akan menghindarkan seseorang dari ketidakpuasan namun tidak menghasilkan kepuasan. Sementara dua kebutuhan lainnya, yaitu kebutuhan akan penghargan dan aktualisasi diri disebut sebagai faktor kepuasan (satisfaction) yang akan menghasilkan perasaan puas atau tidak puas jadi bukan ketidakpuasan. Faktor yang pertama selanjutnya disebut sebagai faktor pemeliharaan (hygiene factors) sedangkan yang kedua disebut faktor motivasi (motivational factors).

Dari sudut pandang lain, faktor pemeliharaan dapat juga disebut sebagai faktor intrinsik, yaitu faktor dalam diri manusia berupa sikap, kepribadian, pendidikan, pengalaman, pengetahuan, dan cita-cita. Sedangkan faktor motivasi dapat disebut faktor ekstrinsik, yaitu faktor dari luar diri manusia berupa kepemimpinan, dorongan atau bimbingan, dan kondisi lingkungan. 3 . Teori Tiga Kebutuhan

Teori ini dikemukakan oleh David Mc Cleland yang berpendapat bahwa pemahaman tentang motivasi akan semakin mendalam apabila disadari setiap orang yang mempunyai tiga jenis kebutuhan.

Tiga jenis kebutuhan yang dimaksud yaitu:
a. Kebutuhan berprestasi, yaitu kebutuhan untuk mendapat prestasi dari setiap hal yang dikerjakan. Contoh menang dalam perlombaan atau lulus kuliah dengan IPK lebih dari 3,50.
b. Kebutuhan afiliasi, yaitu kebutuhan untuk bersahabat atau berinteraksi dengan orang lain.

c. Kebutuhan memperoleh kekuasaan yaitu kebutuhan yang ada pada suatu persaingan dan menginginkan dirinya mempunyai pengaruh yang besar terhadap orang lain.

Menurut David Mc Cleland dikutip dari Ischayati (2011) :

Motif merupakan implikasi dari hasil pertimbangan yang telah dipelajari dengan ditandai suatu perubahan pada situasi afektif. Sumber utama munculnya motif adalah dari rangsangan perbedaan situasi sekarang dengan situasi yang diharapkan, sehingga tanda perubahan tersebut tampak adanya perbedaan afektif saat munculnya motif dan saat usaha pencapaian yang diharapkan.

Tipe-Tipe Kepribadian Big Five Personality terdiri dari lima tipe atau faktor. Terdapat beberapa istilah untuk menjelaskan kelima faktor tersebut. Namun, di sini kita akan menyebutnya dengan istilah-istilah berikut:
1) Neuroticism $(N)$
2) Extraversion $(E)$
3) Openness to New Experience (O)
4) Agreeableness (A)
5) Conscientiousness $(C)$

Untuk lebih mudah mengingatnya, istilah-istilah tersebut di atas disingkat menjadi OCEAN (Pervin, 2005).

Neuroticism berlawanan dengan Emotional stability yang mencakup perasaan-perasaan negatif, seperti kecemasan, kesedihan, mudah marah, dan tegang. Openness to Experience menjelaskan keluasan, kedalaman, dan kompleksitas dari aspek mental dan pengalaman hidup. Extraversion dan Agreeableness merangkum sifat-sifat interpersonal, yaitu apa yang dilakukan seseorang dengan dan kepada orang lain. Yang terakhir Conscientiousness menjelaskan perilaku pencapaian tujuan dan kemampuan mengendalikan dorogan yang diperlukan dalam kehidupan sosial

(Pervin, 2005)

Auditing menurut ASOBAC (A Statement of Basic Auditing Concepts) adalah proses sistematik untuk memperoleh dan mengevaluasi bukti-bukti secara obyektif mengenai pernyataan tentang kejadian dan tindakan ekonomi untuk menentukan tingkat kesesuaian antara pernyataan tersebut dengan kriteria yang ditetapkan dan untuk menyampaikan hasilnya kepada pemakai yang berkepentingan. 
Dilihat dari jenis pemeriksaan yang dilakukan, auditing diklasifikasikan dalam 3 jenis, yaitu:

1. Pemeriksaan laporan keuangan (financial statement audit) Bertujuan untuk menilai kewajaran laporan keuangan yang disajikan klien atas dasar prinsip akuntansi yang berlaku. Pemeriksaan ini dilakukan oleh akuntan publik (external auditor).

2. Pemeriksaan Kepatuhan (complience audit)

Pemeriksaan kepatuhan meliputi pemeriksaan atas aktivitas keuangan atau aktivitas operasi tertentu dengan tujuan untuk menentukan kesesuaiannya dengan kondisi atau aturan tertentu. Kriteria dalam pemeriksaan ini biasanya datang dari penguasa, misalnya pemerintah.

3. Pemeriksaan operasional (operational audit)

Pemeriksaan operasional merupakan pemeriksaan sistematis atau aktivitas operasional organisasi dalam hubungannya dengan tujuan tertentu. Tujuan pemeriksaan ini adalah :

a. Menilai prestasi

b. Mengidentifikasi kesempatan untuk perbaikan

c. Membuat rekomendasi untuk pengembangan dan tindakan lebih lanjut

Pemeriksaan operasional dapat dilakukan manajemen maupun pihak ke tiga.

Auditing dikelompokan juga kedalam tiga jenis sebagai berikut

1. Pemeriksaan Eksternal (External Auditing) Pemeriksaan eksternal adalah suatu kontrol sosial yang memberikan jasa kebutuhan akan informasi untuk pihak luar dari suatu organisasi yang diperiksa. Pemeriksanya adalah pihak luar perusahaan yang independen terhadap perusahaan. Para pemeriksa pada umumnya dibayar oleh manajemen organisasi yang diperiksa.

2. Pemeriksaan Internal (Internal Auditing)

Pemeriksaan internal adalah suatu kontrol organisasi yang mengukur dan mengevaluasi efektifitas organisasi. Informasi yang dihasilkan oleh pemeriksa internal adalah untuk organisasi itu sendiri. Pemeriksanya adalah karyawan organisasi itu sendiri dan tentunya dibayar oleh organisasi itu pula.

3. Pemeriksaan Sektor Publik (Publik Sektor Auditing) Pemeriksaan sektor publik adalah suatu kontrol atas organisasi pemerintah yang memberikan jasanya kepada masyarakat, seperti pemerintah Tingkat satu, pemerintah tingkat dua. Pemeriksanya adalah berasal dari pemerintah (akuntan pemerintah) dan tentunya dibayar oleh pemerintah itu sendiri.

\section{Kerangka Toeritikal Dasar dan Kerangka Penelitian serta Perumusan Hipotesis}

Penelitian ini termasuk penelitian akuntansi keperilakuan. Yaitu meneliti perilaku para mahasiswa yang mau memahami mata kuliah auditing. Variabel-variabel yang mempengaruhi jika digambarkan adalah seperti pada gambar 1 .

\section{Perumusan Hipotesis}

Untuk memperoleh lulusan mahasiswa yang berkualitas, peran dosen tidaklah penting bila tidak diimbangi dengan dorongan dari dalam mahasiswa itu sendiri.

Menurut Purwanto (1990), secara umum tujuan motivasi adalah untuk menggerakkan atau menggugah seseorang agar timbul keinginan dan kemauannya untuk melakukan sesuatu sehingga dapat memperoleh hasil atau mencapai tujuan tertentu.

Menurut Sardiman, motivasi adalah proses yang memberi semangat, arah, dan kegigihan perilaku. Artinya, perilaku yang memiliki motivasi adalah perilaku yang penuh energi, terarah, dan bertahan lama (Sardiman, 2007). Dalam kegiatan belajar, maka motivasi dapat dikatakan sebagai keseluruhan daya penggerak di dalam diri siswa yang menimbulkan kegiatan belajar, yang menjamin kelangsungan dari kegiatan belajar

\section{Gambar 1}

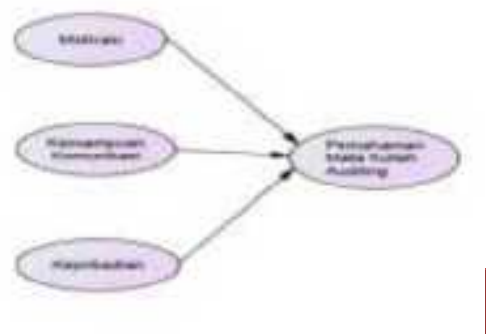


dan memberikan arah pada kegiatan belajar, sehingga tujuan yang dikehendaki oleh subjek belajar itu dapat tercapai (Sardiman, 2000). Oleh karena itu, hipotesis yang diajukan dalam penelitian ini adalah:

H1 :Motivasi Berpengaruh Positif terhadap Pemahaman Mata Kuliah Auditing Kemampuan komunikasi juga dianggap sebagai faktor penting untuk mencapai kesuksesan dalam bidang akuntansi. Pada tahun 1993 ICCA mengeluarkan satuan tugas khusus, yaitu The Skill for The 21th Century Task Force, untuk meneliti masalah yang berhubungan dengan perubahan kebutuhan akuntan pada abad-21. Satuan tugas ini menemukan, bahwa di abad-21,

akuntan yang dibutuhkan adalah yang memiliki kompetensi sebagai berikut: keterampilan akuntansi, keterampilan komunikasi, keterampilan negoisasi, keterampilan interpersonal, kemampuan intelektual, pengetahuan manajerial dan organisasi, serta atribut personal. Kullberg et al. (1989) seperti yang dikutip oleh Aly \& Islam (2003) meneliti delapan Kantor Akuntan Publik terbesar (The Big Eight) dan mengidentifikasi tiga kemampuan yang dibutuhkan agar menjadi sukses dalam profesi akuntan, yaitu kemampuan interpersonal, kemampuan berkomunikasi, kemampuan intelektual.

Kemampuan komunikasi seseorang dapat meningkatkan produktivitas individu maupun kelompok. Setiap orang memiliki kecenderungan terhadap gaya komunikasi tertentu. Hal ini dipengaruhi oleh perpaduan antara hereditas dan faktor lingkungan seseorang. Lebih jauh, proses komunikasi seseorang dipengaruhi oleh gaya komunikasi. Gaya komunikasi merupakan kombinasi dari berbagai komponen, seperti pola suara, gerak mata, ekspresi wajah. Agar dapat berkomunikasi dengan baik, gaya komunikasi haruslah fleksibel, disesuaikan dengan situasi dan gaya komunikasi orang yang diajak berbicara (Franksiska, 2006 ). Oleh karena itu, hipotesis yang dapat diajukan dalam penelitian ini adalah:
H2 : Kemampuan Komunikasi Berpengaruh Positif terhadap Pemahaman Mata Kuliah Auditing Kepribadian seseorang juga mempengaruhi gaya komunikasi seseorang. Apakah orang itu pendiam, pasif, ceria, ambisius ataupun mudah bergaul. Kepribadian merupakan pola perilaku, pikiran, dan emosi yang unik dan relatif stabil yang dimiliki individu dalam

usahanya untuk menyesuaikan diri dan berinteraksi dengan lingkungannya.

Kepribadian terbentuk dari faktor keturunan maupun faktor lingkungan dalam kondisi situasional. Faktor keturunan merujuk pada faktor - faktor yang ditentukan sejak lahir. Sedangkan faktor lingkungan merujuk pada budaya tempat individu dibesarkan, kondisi awal individu, norma keluarga dan kelompok sosial serta pengaruh yang dialami individu sepanjang masa hidupnya. Oleh karena itu, hipotesis yang dapat diajukan dalam penelitian ini adalah: H3 : Kepribadian Mahasiswa Berpengaruh Positif terhadap Pemahaman Mata Kuliah Auditing

\section{METODE PENELITIAN}

Sampel dan Prosedur

1. Obyek Penelitian : dalam penelitian ini obyek penelitian adalah mahasiswa jurusan akuntansi di fakultas ekonomu UNIMUS dan UNISSULA.

2. Cara Pengumpulan Data : Pengumpulan data primer dilakukan dengan penyebaran kuesioner langsung kepada mahasiswa akuntansi di fakultas ekonomi UNIMUS dan UNISSULA

3. Teknik pengolahan data dan analisis menggunakan SEM (Structural Equation Modeling).

\section{Desain Penelitian}

Tujuan penelitian ini adalah untuk mengetahui dan menguji apakah motivasi, kemampuan komunikasi dan kepribadian berpengaruh positif terhadap pemahaman mata kuliah auditing? Motivasi, kemampuan komunikasi dan kepribadian merupakan variabel eksogen. Sedangkan pemahaman mata kuliah auditing merupakan variabel endogen.

Untuk mendapatkan data dilakukan penyebaran kuesioner secara langsung kepada mahasiswa akuntansi yang sudah mendapat mata kuliah auditing di UNIMUS dan UNISSULA.

\section{Pengukuran dan Validitas Variabel}

Data pada variabel-variabel diperoleh dari kuesioner dengan menggunakan indikator-indikator atau pengukuran preferensi persepsi yang membentuk perilaku dengan lima point skala likert. Angka (1) 
memberikan preferensi " sangat tidak setuju" sampai dengan angka (5) memberikan preferensi "sangat setuju". Variabel-variabel tersebut adalah sebagai berikut:

\section{Motivasi}

Variabel ini diukur dengan menggunakan empat indikator ukuran (Evytasari, 2010) yaitu:

a. Kuatnya kemauan untuk belajar.

b. Kesenangan

c. Kemudahan dalam belajar

d. Keinginan atau impian

2. Kemampuan Komunikasi Variabel ini diukur dengan menggunakan empat indikator ukuran (Riswanti, 2010) yaitu:
a. Komunikasi yang baik kepada dosen pengajar
b. Saling berdiskusi
c. Aktif dalam perkuliahan
d. Kesenangan dalam komunikasi

\section{Kepribadian}

Variabel ini diukur dengan menggunakan empat indikator ukuran (Riswanti, 2010) yaitu:
a. Tanggung jawab terhadap tugas
b. Saling menghargai dosen dan mahasiswa
c. Tidak mudah menyerah
d. Sopan dalam segala hal

4. Pemahaman Mata Kuliah Auditing Variabel ini diukur dengan melihat nilai mata kuliah auditing 1 dan auditing 2 .

\section{HASIL PENELITIAN}

\section{Analisis Model Struktural}

Pada bagian ini, sesuai dengan ukuran-ukuran yang dinilai, menggunakan model persamaan struktural. Adapun langkah-langkahnya adalah sebagai berikut:

1. Mengembangkan model berbasis teori.

Pada dasarnya SEM adalah confirmatory technique yang digunakan untuk menguji hubungan kausalitas dimana variabel diasumsikan menghasilkan perubahan pada variabel lain didasarkan pada teori yang ada.

2. Membentuk sebuah diagram alur (path diagram).
Tujuan penggunaan diagram alur adalah untuk menunjukkan hubungan kausalitas. Pada langkah kedua ini akan dikemukakan bentuk diagram alur (path diagram) untuk menggambarkan hubungan kausalitas dari konstruk.

3. Menterjemahkan diagram alur tersebut ke dalam persamaanpersamaan struktural (structural equation).

Setelah mengembangkan model teoritis dalam diagram alur, maka langkah selanjutnya adalah menerjemahkan dalam bentuk persamaan.

4. Memilih matriks input dan teknik estimasi.

Model persamaan struktural berbeda dari teknik analisis multivariate lainnya, SEM hanya menggunakan data input berupa matrik varian/kovarian atau matrik korelasi (Ghozali, 2008).

5. Menilai identifikasi model.

Problem identifikasi adalah ketidak mampuan proposed model untuk menghasilkan unique estimate (Ghozali, 2008).

6. Mengevaluasi kriteria Goodness-offit.

Pada langkah keenam ini kesesuaian model dievaluasi dengan telaah berbagai kriteria goodness-of-fit. Ada beberapa kriteria yang dapat digunakan untuk melihat suatu model diterima atau ditolak, yaitu:

a. Chi square (\%2), digunakan untuk mengukur overall fit. Model yang baik atau memuaskan jika nilai $\mathrm{x}$ rendah. Semakin kecil nilai $\mathrm{x}^{2}$ maka dapat dikatakan model tersebut semakin kuat.

b. Significance probability, digunakan untuk menguji tingkat signifikansi model.

c. The minimun sample discrepancy funcion (CMIN) adalah menggambarkan perbedaan antara unrestricted sample covariance matrix $\mathrm{S}$ dan restricted covariance matrix $\mathrm{X}(0)$ atau secara esensi menggambarkan likelihood ratio test statistic yang umumnya dinyatakan dalam Chi-square $\left(\mathrm{x}^{2}\right)$ statistic.

d. Googness-of-fit indeks (GFI), merupakan bagian dari absolute fit measure yaitu ukuran nonstatistik yang nilainya berkisar 
dari nilai 0 (poor fit) hingga 1,0 (perfect fit). Nilai GFI yang tinggi menunjukkan fit yang lebih baik dan nilai GFI yang dianjurkan oleh banyak peneliti adalah $>0.90$.
e. Root Mean
Ofapproximation
Square Error merupakan
bagian
(RMSEA),

Tabel 2

Koefisien Pengukuran Estimasi

\begin{tabular}{|c|c|c|}
\hline \multicolumn{1}{c}{ Hipotesa } & C.R & p value \\
\hline H1 & 3,304 & 0,000 \\
H2 & 1,327 & 0,185 \\
H3 & 1,649 & 0,099 \\
\hline
\end{tabular}

\begin{tabular}{lccr}
$\begin{array}{l}\text { absolute } \\
\text { ukuran }\end{array}$ & yang & meansure & yaitu \\
mencoba \\
memperbaiki & \multicolumn{2}{r}{ kecendrungan } \\
statistic & \multicolumn{4}{c}{ chi-square } & menolak \\
model dengan & jumlah & sempel \\
yang & besar. & Nilai & RMSEA \\
antara & 0.05 & hingga & 0.08 \\
merupakan & ukuran yang & dapat \\
diterima. & Hasil & uji & empiris \\
RMSEA & cocok untuk & menguji \\
model & konfirmatori & dengan
\end{tabular}
jumlah sampel besar.

f. Tucker Lewis Index (TLI), Digunakan untuk
membandingkan model yang diuji dengan baseline model. Nilai yang direkomendasikan sama atau lebih besar dari 0.90 dan nilai yang mendekati 1 menunjukan very good fit. g. Comparative Fit Indeks (CFI), merupaka rasio antara selisih dari terget model dengan perbedaan dari model bebas. CFI mempresentasikan sejauh mana model keterikatan lebih baik dibanding model bebas.

Tabel 1

Goodness-of-Fit Index Full Structural

\begin{tabular}{|c|c|c|c|}
\hline \multicolumn{4}{|c|}{ Equation Model } \\
\hline $\begin{array}{l}\text { Goodnes } \\
\text { s-of-Fit } \\
\text { Index }\end{array}$ & $\begin{array}{c}\text { Cut-off } \\
\text { Value }\end{array}$ & $\begin{array}{l}\text { Hasil } \\
\text { Model }\end{array}$ & $\begin{array}{l}\text { Keter } \\
\text { angan }\end{array}$ \\
\hline $\begin{array}{l}\text { Chi- } \\
\text { Square }\end{array}$ & $\begin{array}{l}\text { Diharapk } \\
\text { an kecil }\end{array}$ & 60.980 & Fit \\
\hline $\begin{array}{l}\text { Probabil } \\
\text { ity }\end{array}$ & $a=d f$ & 0.014 & Fit \\
\hline \begin{tabular}{|l} 
CMIN/D \\
F
\end{tabular} & $<2.0$ & 1.564 & Fit \\
\hline GFI & $<0.90$ & 0.904 & $\begin{array}{c}\text { Margi } \\
\text { nal }\end{array}$ \\
\hline RMSEA & 0.050 .08 & 0 D/AKS & MGiM \\
\hline TLI & $>0.90$ & 0.932 & Fit \\
\hline CFI & $>0.90$ & 0.951 & Fit \\
\hline
\end{tabular}

Nilai CFI yang dianjurkan oleh banyak peneliti adalah > 0.90 sebagai ukuran goodfit. 7. Interpretasi dan modifikasi model. Ketika model dinyatakan diterima, maka peneliti dapat

mempertimbangkan dilakukannya modifikasi model untuk memperbaiki penjelasan teoritis atau goodness-of-fit. Modifikasi dari model awal harus dilakukan setelah dikaji banyak pertimbangan

(Ghozali, 2008).

Berikut ini ditampilkan ringlasan perbandingan antara nilai fit model yang dibangun dengan ukuran fit yang telah ditetapkan.

Selanjutnya kita memeriksa parameter standar pada tabel 2. Parameter standar estimasi antara motivasi dan pemahaman mata kuliah auditing distributif adalah positif dan signifikan $(\mathrm{p}<\mathrm{.001}), \mathrm{H} 1$ diterima. Selanjutnya estimasi parameter standar antara kemampuan komunikasi dan pemahaman mata kuliah auditing adalah tidak signifikan (p>.001), H2tidak diterima. Sedangkan parameter standar estimasi antara kepribadian dan pemahaman mata kuliah auditing distribitif adalah positif dan signifikan ( $\mathrm{p}$ $<, 10), \mathrm{H} 3$ diterima.

\section{DAFTAR PUSTAKA}

Affandi, Irfan. 2011. "Faktor-Faktor Yang Mempengaruhi Prestasi Belajar Mahasiswa Dalam Mata Kuliah Pemeriksaan Akuntansi II (Studi Empiris Pada Mahasiswa Akuntansi Upn"Veteran"Jawa Timur) ". Jawa Timur: Universitas Pembangunan Nasional "Veteran" Jawa Timur.

Aly, I.M. dan Islam, M. 2003. "Audit of Accounting Program on Oral Communications Apprehention: Comparative Study among Accounting Students". Managerial Auditing Journal, pp 751-760

Arikunto, Suharsimi. 2002. Prosedur Penelitian suatu Pendekatan Praktek. Jakarta: Rineka Cipta.

Budhiyanto, Suryanti J. Dan Nugroho, Ika P., 2004, "Pengaruh 


\section{Kecerdasan Emosional} terhadap Tingkat Pemahaman Akuntansi", Jurnal Ekonomi Bisnis, Vol. X, No.2, Hal.260-281

Cangara, Hafied. 2006. Pengantar Ilmu Komunikasi. Jakarta: Rajawali Pers.

Dorland, W.A. Nerman. 2002. Kamus Kedokteran Dorlan Edisi 29. Jakarta: EGC Jakarta.

Evytasari. Aditya A. 2010. "Pengaruh Pengendalian Diri, Motivasi Dan Minat Belajar Terhadap Tingkat Pemahaman Akuntansi (Studi Kasus Pada Mahasiswa Akuntansi Upn "Veteran" Jawa Timur)". Jawa Timur: Universitas Pembangunan Nasional "Veteran" Jawa Timur.

Ferdinan, Augusty. 2006. Structural Equation Model dalam penelitian manajemen: Aplikasi model-model rumit dalam penelitian untuk tesis magister dan disertasi doctor. Semarang: Badan Penerbit Universitas Diponegoro.

Ghozali, Imam. 2006. Aplikasi Analisis Multivariate dengan Program SPSS. Semarang: Badan Penerbit Universitas Diponegoro.

Ghozali, Imam. 2008. Model Persamaan Struktural Konsep dan Aplikasi dengan Program AMOS 16.0. Semarang: Badan Penerbit Universitas Diponegoro

Hair J. F., Amderson R. E., Tatham R. L., and Black W. C. 1998. Multivariate Data Analysis: Fifth Edition. New Jersey: Prentice Hall Inc.

Halim, Abdul. 2003. Auditing 1 (Dasar-Dasar Audit Laporan Keuangan). Yogyakarta: UPP AMP YKPN.

\begin{tabular}{lcrl} 
& \multicolumn{2}{c}{ Halim, Abdul dan Totok Budi S. } \\
Auditing & 2004. & \\
Prosedur & 2 & (Dasar-Dasar Pengauditan \\
Laporan & & & Keuangan. \\
Yogyakarta: & UPP & AMP & \\
YKPN. & & &
\end{tabular}

Kunartinah. 2003. "Faktor yang mempengaruhi Pemilihan karir Sebagai Akuntan Publik". Jurnal Bisnis dan Ekonomi (JBE), Vol.10 No.2, Semarang: P3m STIE Stikubank

Nisfinnoor, Muhammad. 2009.

Pendekatan Statistika Modern untuk ilmu sosial. Jakarta: Salemba Humanika

Permatasari, Dian A. 2011. "Pengaruh Beberapa Faktor terhadap Tingkat Pemahaman Akuntansi pada Mahasiswa Akuntansi di Universitas Pembangunan Nasional "Veteran" Jawa Timur". Jawa Timur: Universitas Pembangunan Nasional "Veteran" Jawa Timur.

Pervin, Lawrence A. 2005. Handbook of Personality: Theory and Research.

Purwanto. 2002. Psikologi pendidikan bandung: PT. Remaja Rosdakarya RI. 2003.

Undang_Undang RI No 20 Tahun 2003 Tentang Sistem Pendidikan Nasional. Jakarta: CV. Eka Jaya.

Purwanto, Djoko. 2002. Komunikasi Bisnis. Surakarta: Erlangga

Riswanti, Hanum A. 2010. "Pengaruh Kemampuan Komunikasi, $\begin{array}{lrr}\text { Berpikir } & \text { Kritis, } & \text { Dan } \\ \text { Kepribadian } & & \text { Terhadap }\end{array}$ Pemahaman Akuntansi Mahasiswa (Studi Kasus Pada Mahasiswa Akuntansi Upn "Veteran" Jawa Timur)". Jawa Timur: Universitas Pembangunan Nasional "Veteran" Jawa Timur.

Sardiman. 2000. Interaksi \& Motivasi Belajar Mengajar. Jakarta: Rajawali Pers.

Sevilla, Consuelo G. et. al (2007). Research Methods. Rex Printing Company. Quezon City.

Siagian, Sondang P. 2004. Teori motivasi dan aplikasinya. Jakarta: Rineka cipta. 
Solimun. 2004. Structural Equation Modelling. Aplikasi Software Amos. FMIPA \& PPS Universitas Brawijaya, Malang

Sugiyono. 2010. Statistik Penelitian. untuk Bandung: Alfabeta.
Supratiknya. 2000. Teori-Teori Holistik. Yogjakarta: Kanisius

Suwardjono, 1999, "Mamahamkan Akuntansi Dengan Penalaran dan Pendekatan Sistem'. Jurnal Ekonomi dan Bisnis Indonesia, Vol. 14 No.3, 106122. 